\title{
Os sentidos atribuídos ao cuidar na infância
}

\section{The meanings attributed at caring for children}

J erto Cardoso da Silva*

Universidade de Santa Cruz do Sul - UNISC, Santa Cruz do Sul, RS, Brasil

Clarissa J unqueira Lopes**

Universidade de Santa Cruz do Sul - UNISC, Santa Cruz do Sul, RS, Brasil

Jéssica Natália Canello**

Universidade de Santa Cruz do Sul - UNISC, Santa Cruz do Sul, RS, Brasil

\section{I ntrodução}

Atravessados pelos discursos e pelas políticas públicas de saúde, os profissionais dessa área vão construindo seus próprios discursos, que se materializam em práticas denominadas cuidados de saúde. Assim, estamos diante de um campo de análise importante, pois estes profissionais prestam serviços, direta ou indiretamente, a maioria da população brasileira.

Através da análise do discurso de profissionais de saúde, que atendem à criança, e de seus procedimentos cotidianos de trabalho, ou seja, de práticas de cuidados, podemos investigar os processos discursivos aos quais estão atrelados. Pretendemos, com este estudo, desvelar alguns sentidos e suas condições de produção. Faz-se, então, necessário refletir sobre a práxis destes profissionais, as suas formas de cuidar e os sentidos que fundam e constituem seus procedimentos.

Este relato é parte de uma pesquisa que visa verificar os sentidos construídos sobre o sintoma, o cuidado e os indicadores de alta apontados por 37 profissionais de saúde mental (enfermeiros, médicos, nutricionistas e psicólogos) no Vale do Rio Pardo/RS. O presente estudo busca problematizar os significados apontados por sete profissionais psicólogos sobre o cuidar em sua prática clínica com crianças, relacionando-os com o atendimento de adultos.

Ao se propor uma noção de cuidado à saúde, simultaneamente, se constrói o seu contrário, isto é, aponta-se para um estado de nãocuidado-à-saúde que se denomina doença, campo moderno do biopoder das ciências biomédicas. Dessa forma, passamos a trabalhar nos discursos sobre o cuidado à saúde com um binômio indissociável: o de saúde-doença. Foucault (1985, p. 58) ainda ressalta que os cuidados de si ou o cuidado que se tem com o cuidado que os outros devem ter desvelam uma intensificação das relações sociais nas quais 
jogos de poder e dominação do outro sobre si e de controle sobre os corpos - superfície de inscrição das normas e valores - estão atualizando relações de poder e práticas discursivas.

Ressaltamos que as práticas de cuidado à saúde estão intimamente vinculadas ao momento histórico ao qual elas vão sendo produzidas. Quanto ao conceito de cuidado, observamos que a designação origina-se do pensar, meditar, considerar, refletir, conceber, preparar - cogitar que é fonte do verbo português cuidar (do século XIII), ou seja, a designação aparece ligada mais ao raciocínio sobre o evento, o que chamamos hoje de diagnóstico (avaliação do sintoma). No século XVII, com o advento de novos modos de produção alavancados pela Revolução Industrial, forja-se o pensar e fazer como partes distintas e separadas. O cuidar vincula-se ao procedimento, e o pensar, tomado como mais importante, relaciona-se a avaliação diagnóstica. Cuidar e avaliar passam a ser partes separadas pela divisão do trabalho e valoradas de forma desigual (HOUAISS, 2001).

\section{Metodologia}

Trata-se de um estudo qualitativo e exploratório, no qual utilizou-se a Análise de discurso de tendência francesa. Segundo Michel Pêcheux, o objetivo da Análise de Discurso é a realização de uma reflexão maior dos significados discursivos e suas formas de produção de sentido.

Pêcheux (1990) propõe que, ao trabalhar o discurso, deve-se dar primado a gestos de descrição das materialidades discursivas e, ao mesmo tempo, ratificar a existência de um real específico a essa materialidade; isto é, trabalhar a materialidade lingüística sem, contudo, compreendê-la como um sistema fechado em si mesmo. Ao trabalhar nos deslizamentos, nos fluxos, nas repetições e transformações dos sentidos, tentamos transpor a sua linearidade. Movemo-nos, então, nessa dimensão que chamamos de entremeio, entre a materialidade do discurso e seu exterior constitutivo.

Com esses pressupostos, realizamos as análises dos depoimentos de sete psicólogos vinculados a diferentes serviços públicos de saúde que atendem à infância, comparando-os com o arquivo principal da pesquisa que tinha o enfoque no atendimento com adultos. Selecionamos várias seqüências discursivas que compuseram o nosso corpus e selecionamos algumas que se transformaram em unidades discursivas de análise. Segundo Orlandi (1999), o analista, ao delimitar o seu corpus, já está diante de um gesto de interpretação que se estende até a análise pontual das seqüências. A interpretação "se tece na historicidade e nos efeitos da língua, na ideologia, e na materialização dessa". 


\section{Resultados e discussão}

Como pode ser visto na Tabela I, apresentamos uma visão geral dos sentidos atribuídos pelos psicólogos sobre o cuidar na infância, comparando-os com os sentidos atribuídos ao cuidar na vida adulta.

\section{Tabela I}

Categorias mais citadas pelos entrevistados sobre o cuidar

\begin{tabular}{ll}
\hline \multicolumn{1}{c}{ Atendimento de crianças } & \multicolumn{1}{c}{ Atendimento de adultos } \\
\hline Integralidade & Procedimentos \\
\hline Aliviar o sofrimento/sintoma & Integralidade \\
\hline Relação com os pais & Atenção ao paciente \\
\hline Olhar sistêmico & Estabelecimento de vínculo \\
\hline Escuta & Atendimento de grupo \\
\hline Atendimento de grupo & Acolhimento/Triagem \\
\hline Psicoterapia & \\
\hline Cuidado especializado individual \\
\hline Encaminhamentos \\
\hline Busca/promoção de autonomia \\
\hline
\end{tabular}

Uma das principais diferenciações, nos sentidos relatados sobre o cuidar na infância, está relacionada à dimensão social, ou seja, apontam para a importância do discurso e do cuidado dos pais. Destaca-se, nos discursos dos profissionais, a necessidade de um olhar sistêmico e de forma integrada nos cuidados à infância. Assim, percebemos que o outro é parte constitutiva na assistência às crianças.

Em relação aos adultos, o que encontramos é um cuidado centrado no próprio paciente, nos procedimentos técnicos. No entanto, a integralidade é apontada como um dos sentidos mais frequentes, no qual, ao se pensar o cuidado da pessoa como um todo, subentendese a dimensão social. Notamos que os sentidos vinculados a prática tecnicista de procedimentos e cuidados especializados parecem ser ainda o foco no cuidado em saúde, quando pensamos nos sentidos apontados no cuidado aos adultos. Por outro lado, pensar a relação, a dimensão social como um fator de cuidado tão importante quanto os procedimentos técnicos, aparece de forma mais significativa na infância 


\section{Conclusão}

O cuidado à saúde foi se constituindo como um campo de construção de práticas cuidadoras, socialmente determinadas, dentro do qual o modo médico de agir e seus procedimentos foram se tornando hegemônicos. Mesmo assim, percebem-se multiplicidades de maneiras de ação (MERHY, 2004). Uma implicação mais séria do modelo biomédico é a de silenciar outras dimensões importantes no cuidado em saúde, em particular, no que se refere à infância, pois fica fixado na atenção sobre o corpo biológico em detrimento das relações sociais. Assim, torna-se premente dar voz às diferentes práticas e discursos que são fomentados no cotidiano de trabalho dos profissionais de saúde que enfatizam a relevância de não se reduzir o cuidado a esfera tecnicista.

Os trabalhadores apresentam intervenções nos processos de saúde marcadas pela relação entre seus núcleos de competência específicos, associados à dimensão de cuidador que qualquer profissional de saúde detém. Ao considerarmos os processos de produção de saberes como baseados nas muitas vozes em ação nos serviços de saúde, falamos de um trabalho em equipe que é resultado de várias forças e saberes que se tensionam nas atuações dos profissionais e no reconhecimento ou não do saber do outro. É fundamental um trabalho em equipe no qual cada trabalhador integre as ações da equipe e se responsabilize coletivamente pelo cuidado, e o remeta a um compartilhar de saberes e fazeres que somente terá lugar quando essas diferentes vozes forem escutadas.

\section{Referências Bibliográficas}

FOUCAULT, M. História da sexualidade, v. 3: o cuidado de si. Rio de Janeiro: Edições Graal, 1985.

HOUAISS, Antônio. Dicionário eletrônico Houaiss da língua portuguesa. Versão 1.0, 2001.

MERHY, E. E. O Ato de Cuidar: a Alma dos Serviços de Saúde. In: Brasil. Ministério da Saúde. Secretaria de Gestão do Trabalho e da Educação na Saúde. Departamento de Gestão da Educação na Saúde. Ver - SUS Brasil: cadernos de textos. Brasília: Ministério da Saúde, 2004, p. 108-137. (Série B. Textos Básicos de Saúde).

ORLANDI, E. P. Análise de Discurso: princípios \& procedimentos. Campinas: Pontes, 1999.

PÊCHEUX, Michel (1982). Delimitações, inversões, deslocamentos.

Cadernos de Estudos Lingüísticos, n. 19, p. 7-24, 1990.

\section{Endereço para correspondência}

J erto Cardoso da Silva

Av. Independência, 2293, CEP 96815-900,Santa Cruz do Sul - RS, Brasil

Endereço eletrônico: jerto@unisc.br 
Clarissa J unqueira Lopes

Rua General Osório, 920/22, CEP 96640-000, Rio Pardo- RS, Brasil

Endereço eletrônico: cla_jl@yahoo.com.br

Jéssica Natália Canello

Linha Terceira Moresco, SN, CEP 95980-000,Anta Gorda - RS,Brasil

Endereço eletrônico: jessicacanello@mx2.unisc.br

Recebido em: 02/12/2010

Aceito para publicação em: 10/01/2011

Acompanhamento do processo editorial: Ariane P. Ewald e Jorge Coelho Soares

Notas

* Doutor, Professor do Departamento de Psicologia da Universidade de Santa Cruz do Sul- UNISC, Santa Cruz do Sul, RS, Brasil

**Acadêmica do curso de Psicologia da Universidade de Santa Cruz do Sul- UNISC, Santa Cruz do Sul, RS, Brasil 